\title{
Monopólios naturais e licitações de serviços públicos
}

\author{
Egon Bockmann Moreira*
}

A "Consulente" honrou-me com pedido de parecer a propósito dos fatos a seguir narrados. O pedido veio instruído com todos os documentos pertinentes ao exame do caso concreto. A sintética descrição da questão fática posta a exame é essencial para a apreciação da consulta.

\section{A situação fática e os quesitos formulados}

1. A Consulente é pessoa jurídica de direito privado, com sede na cidade de "B.". A sociedade atua desde 1996 com rede de esgotos própria (devida e formalmente autorizada pelo município), especificamente na coleta e tratamento de resíduos industriais. ${ }^{1} \mathrm{~A}$ estação de tratamento de propriedade da Consulente tem capacidade ociosa, vez que utiliza cerca de $40 \%$ (quarenta por cento) de sua potência.

Ocorre que, desde 1995, a cidade de "B." possui rede coletora de esgoto doméstico - até hoje sem utilização. Com efeito, somente há o projeto da Prefeitura Municipal para a implementação de plano de saneamento (abaste-

\footnotetext{
* Professor de direito econômico da Faculdade de Direito da UFPR. Mestre e doutor em direito do Estado. Pós-Graduado em regulação pública e concorrência pela Faculdade de Direito da Universidade de Coimbra. Advogado - OAB/PR 14.376.

${ }^{1}$ A coleta de resíduos industriais alberga, também, o tratamento de esgoto de cerca de 5.500 (cinco mil e quinhentos) empregados das indústrias da região.
} 
cimento de água potável, esgotamento sanitário, limpeza urbana e manejo de resíduos sólidos, drenagem e manejo de águas pluviais urbanas).

Existe, portanto, uma rede de infraestrutura com capacidade ociosa conjugada com a demanda pública já formalizada no plano de saneamento municipal. Ocorre que é viável, técnica e economicamente, a conexão da rede de esgotos já existente na cidade com a rede coletora da Consulente, o que pode ser implementado pela construção de ramais e estações elevatórias, a baixo custo e com pouca interferência no sistema viário da cidade. A infraestrutura necessária, em resumo, está praticamente completa.

De qualquer forma, fato é que o valor dos investimentos relativos às obras necessárias para interligar os sistemas (o da Consulente e o já existente na cidade), incluindo-se aqui as estimativas de melhorias e serviços de reparação na rede de esgoto doméstica, é significativamente menor do que os necessários para a construção de toda uma nova rede, elevatórias e estação de tratamento.

2. Justamente aí reside o ponto principal do presente parecer, qual seja, da validade (ou não) da contratação de empresa outra, que não a Consulente, para a prestação do serviço de saneamento na cidade de "B.". Para tanto, são formulados os seguintes quesitos:

a. A prestação de serviços de saneamento, em específico a coleta de esgoto para posterior tratamento, constitui um monopólio natural?

b. É juridicamente válida a instauração de licitação para a construção duplicada de rede de esgotos e tratamento à semelhança daquela já existente?

c. Pode a administração pública fazer escolhas discricionárias no caso em concreto, para a implantação de nova rede paralela à já existente?

Passo ao exame do caso concreto.

\section{Considerações preliminares: o exame do caso concreto como premissa cognoscitiva}

3. O presente parecer versa a respeito de uma cidade que já conta com infraestrutura destinada a coleta e tratamento de esgotos sanitários, hábil a promover a integralidade do ciclo técnico da atividade para toda a demanda municipal. Este fato é incontroverso. Neste contexto, a administração 
pública já decidiu que é necessário o fornecimento de tais serviços para toda a população urbana - esta escolha administrativa, a configurar o interesse público posto em jogo, já foi tomada. O que resta, então, é a decisão quanto ao modo pelo qual esta escolha será concretizada: se por meio da rede já instalada ou mediante sua duplicação. Neste caso, como em tantos outros, a análise dos fatos é decisiva para a validade do ato administrativo a ser praticado.

Por isso que não se pode abdicar da consideração minuciosa da situação fática, a fim de se desenhar com precisão a situação jurídica dela advinda. O caso concreto, no processo de aplicação normativa, é a mais fiel premissa cognitiva que permite a construção da solução adequada à Constituição brasileira. Está-se a defender a leitura do direito que preze as circunstâncias do caso concreto e instale a interpretação efetiva da realidade posta pela norma jurídica (não dela descolada e muito menos que a menospreze). Afinal, como leciona Eros Grau:

O intérprete discerne o sentido do texto a partir e em virtude de um determinado caso dado; a interpretação do direito consiste em concretar a lei a cada caso, isto é, na sua aplicação [Gadamer]

\section{$[\ldots]$}

Vou repetir, mais uma vez: a norma é produzida, pelo intérprete, não apenas a partir de elementos colhidos no texto normativo (mundo do dever ser), mas também a partir de elementos do caso ao qual será ela aplicada, isto é, a partir de dados da realidade (mundo do ser). ${ }^{2}$

Assim, o caso concreto não é um dado secundário (ou posterior) à aplicação do direito, mas, na dicção de Castanheira Neves, configura um prius metodológico, "verdadeiramente a perspectiva problemática-intencional que tudo condiciona e em função da qual tudo deverá ser interrogado e resolvido". ${ }^{3}$ Os fatos são as condicionantes primárias do processo de aplicação normativa.

\footnotetext{
${ }^{2}$ GRAU, Eros. Ensaio e discurso sobre a interpretaçãolaplicação do direito. 3. ed. São Paulo: Malheiros, 2005. p. 31. No mesmo sentido, quanto aos motivos de fato do ato administrativo, v. MELLO, Celso Antônio Bandeira de. Curso de direito administrativo. 25. ed. São Paulo: Malheiros, 2008. p. 112-113; e MOREIRA, Egon Bockmann. Processo administrativo. 4. ed. São Paulo: Malheiros, 2010. p. 372-375.

${ }^{3}$ NEVES, Castanheira. Metodologia jurídica. Coimbra: Coimbra Ed., 1993. p. 142.
} 
4. A constatação assume dimensão superior no plano da aplicação da Constituição (art. 37, caput, e inc. XXI). “Não existe interpretação constitucional independente de problemas concretos", pontifica Konrad Hesse. ${ }^{4}$ Enfim, a Constituição se interpreta e é aplicada tendo em vista o caso concreto; não em função de abstrações porventura formuladas pelo intérprete. E a aplicação do texto constitucional tem natureza eminentemente constitutiva, não apenas declaratória. Aquele que porventura pretender aplicar a norma desprezando os fatos estará lançando qualquer interpretação, menos aquela que possa ser qualificada como válida para o caso concreto.

Tendo em vista tais premissas será desenvolvido este parecer.

\section{A infraestrutura de saneamento como um monopólio natural}

5. Conforme esclarecido na exposição fática, a Consulente é empresa que se dedica à coleta e tratamento de resíduos sólidos e líquidos, contando com infraestrutura autorizada para a prestação de tal atividade. Se é certo que as atividades econômicas ordinárias são, em geral, prestadas em concorrência com diversos prestadores (Constituição, art. 170 e incisos), é igualmente necessário que se observe que algumas atividades, tendo em vista suas características próprias, simplesmente não podem ser prestadas por mais de uma empresa. Fala-se aqui em monopólio natural.

6. Monopólios são situações nas quais há só um agente econômico no polo da oferta de determinado bem ou serviço. De usual (sobretudo para os economistas ditos neoclássicos), o monopólio é considerado uma falha de mercado. Afinal, os economistas estão às voltas com realidades complexas e imperfeitas. Estudam teoricamente a concorrência perfeita para, a partir de seus pressupostos, tentar corrigir as respectivas imperfeições, chamadas tecnicamente de "falhas de mercado" (monopólios, oligopólios, assimetria de informações, externalidades etc.). Os estudiosos das relações econômicas têm, portanto, que construir uma referência com a qual se pode comparar a realidade. $\mathrm{O}$ referencial existe em termos de eficiência econômica:

\footnotetext{
${ }^{4}$ HESSE, Konrad. Elementos de direito constitucional da República Federal da Alemanha. Tradução de L. A. Heck. Porto Alegre: S.A. Fabris, 1998. p. 62.
} 
como se desenvolver a atividade de forma a promover maiores benefícios sociais a um menor custo.

Neste cenário, a concorrência perfeita é a referência: trata-se do ambiente onde compradores e vendedores são perfeitamente informados e não há falhas no mercado. Há vendas a preço ideal de quantidades ideais. Nesse contexto fictício, apenas vendedores e compradores transacionam no mercado, sem qualquer intervenção do Estado. A ausência de falhas conduz ao ótimo social e à melhor distribuição de riqueza. Por isso que o monopólio é tido como uma falha, um defeito deste mercado idealizado.

7. Porém, a ciência econômica constatou empiricamente - e o direito econômico referendou tal constatação - que há casos em que o monopólio não configura propriamente uma falha, mas sim o único modo de produção de certo bem ou prestação de determinado serviço. Aqui não está em jogo a vontade - ou a cobiça - dos agentes econômicos, mas a realidade fática. $\mathrm{O}$ mundo dos fatos dita as regras daquele mercado e não permite que haja dois ou mais agentes prestando as mesmas atividades - pena de este desvio conduzir todos os envolvidos a situações de brutal ineficiência (e mesmo de quebra), com custos irrecuperáveis.

A expressão monopólio natural retrata a situação fática em que é economicamente ineficiente (senão impossível) a instalação de mais vários operadores para o desenvolvimento de específica atividade econômica, "no sentido de a estrutura do mercado tornar mais eficiente a presença de um único produtor do que a presença de vários" ${ }^{\prime 5}$ - seja devido a custos fixos muito elevados, seja em razão de economias de escala.

Como descreve Fábio Nusdeo, o monopólio natural

corresponde na maioria das vezes a uma atividade na qual os custos de produção fixos, representados sobretudo pela maquinaria, instalações e base territorial são desproporcionalmente elevados em relação aos custos variáveis, correspondentes principalmente a matérias-primas, energia e mão de obra. [...] Seriam pois as próprias condições estru-

\footnotetext{
${ }^{5}$ ARAÚJO, Fernando. Introdução à economia. Coimbra: Almedina, 2002. p. 348. Aprofundar em MOREIRA, Egon Bockmann Direito das concessões de serviços públicos. São Paulo: Malheiros, 2010. p. 335-340.
} 
turais-tecnológicas desses setores a impedirem a sua organização em regime de concorrência. ${ }^{6}$

Note-se que é exatamente este o conceito dado por Marçal Justen Filho, ao definir o monopólio natural como a "situação econômica em que a duplicação de operadores é incapaz de gerar a redução do custo da utilidade". ${ }^{7}$ A mesma ideia é trazida por Richard Schmalensee: "uma indústria ou atividade é dita como monopólio natural se a produção for mais eficiente se feita por apenas uma firma individual ou entidade." 8

Em suma, nas situações fáticas de monopólio natural é ineficiente a multiplicação de infraestruturas e de agentes no polo de oferta dos bens e serviços. Caso algum aventureiro opte por duplicar tais infraestruturas, estará adotando uma escolha péssima na administração de suas finanças.

8. Isto é, a situação de monopólio natural não merece ser entendida como privilégio a certo agente econômico, mas sim significa que aquele bem ou serviço só pode ser prestado de forma eficiente se o for por uma só empresa. Constatação que se acentua nos serviços públicos - os quais, por definição constitucional, devem ser prestados ao cidadão. Por isso que se dá a existência, em determinados contratos públicos, da proibição de ingresso de novos agentes - direitos de exclusividade expressos ou que resultem “implicitamente da obrigação, que a Administração concedente assume, de não atribuir a empresas terceiras títulos para a exploração de atividades concorrentes ou que possam fazer concorrência ao concessionário (pactum de non licitanto)". ${ }^{9}$ Logo, e a depender das peculiaridades deste ou daquele serviço público, ele só poderá ser prestado por um e somente um concessionário (ou permissionário ou autorizado). A existência de mais de um prestador exigirá a criação de mercados artificiais a custos públicos perdi-

\footnotetext{
${ }^{6}$ NUSDEO, Fábio. Curso de economia: introdução ao direito econômico. 5. ed. São Paulo: Revista dos Tribunais, 2008. p. 274.

${ }^{7}$ JUSTEN FILHO, Marçal. Serviço público no direito brasileiro. RDPE, v. 7, n. 161, 2004.

${ }^{8}$ SCHMALENSEE, Richard. The control of natural monopolies. Lexington: Lexington Books, 1979. p. 3 (tradução livre). Ampliar em VARIAN, Hal R. Intermediate microeconomics. $5^{\text {th }}$. ed. New York: W.W. Norton, 1999. p. 425-427; VISCUSI, W.K.; VERNON, J.M.; HARRINGTON JR., J.E. Economics of regulation and antitrust. $3^{\text {rd }}$. ed. Cambridge: MIT Press, 2001. p. 337-358; e WATERSON, Michael. Regulation of the firm and natural monopoly. Oxford: Basil Blackwell, 1988, passim.

${ }^{9}$ GONÇALVES, Pedro. A concessão de serviços públicos. Coimbra: Almedina, 1999. p. 266. Trata-se, portanto, de dever do concedente correlativo ao direito subjetivo do concessionário (ou permissionário ou autorizado). Pense-se nos exemplos de linhas de ônibus ou de uma ponte cuja rentabilidade em longo prazo exija a ausência de outras pontes numa distância mínima.
} 
dos (com a respectiva indenização ao particular a quem foi originalmente adjudicado o serviço).

Um dos exemplos clássicos de monopólio natural é o da instalação de rede de água, esgotamento e tratamento sanitário: até a presente data não se encontrou solução - técnica ou econômica - que permitisse a concorrência do lado da oferta, pois são exigidos investimentos iniciais imobilizados muito elevados, com retorno em longo prazo e risco significativo..$^{10}$ Outros exemplos são aqueles serviços que também envolvem infraestruturas com custos elevados, alguns dos quais vêm sendo atenuados com o avanço tecnológico (ferrovias, telefonia fixa, rede de energia elétrica etc.).

Imagine-se, para tornar o entendimento mais claro, a construção de infraestrutura de coleta e transporte de resíduos, a rede de esgotos propriamente dita, em duplicidade: seria ilógico, desarrazoado e desproporcional supor a possibilidade de construção e manutenção de duas redes de esgoto, tratamento e reservatórios em uma mesma localidade. A impossibilidade física de escolha por parte dos usuários salta aos olhos (afinal, como se daria a ligação nesta ou naquela rede e a eventual mudança nos prestadores?).

Some-se a isso o fato de que, em que pese haver impossibilidade lógica de se concluir pela viabilidade de tal situação, deve-se reconhecer que a remuneração satisfatória do prestador do serviço restaria impossibilitada, pois é pressuposto básico para a manutenção do empreendimento que haja número suficiente de usuários, o que não pode ocorrer em um regime supostamente concorrencial ante o monopólio natural.

9. A questão enquadra-se perfeitamente no caso em análise, visto que os custos de manutenção da rede de saneamento são fixos e elevados, de forma que a remuneração do agente prestador do serviço, assim como o preço final ao usuário só serão satisfatórios quando fornecidos por apenas uma empresa: "quanto maior o número de usuários do sistema, menor o custo

\footnotetext{
10 "Several of the classic public utilities industries, such as water and sewer services and the local distribution of gas and electricity, involve networks along which something is transmited from (or to) a relatively small number of locations to (or from) a relatively large number of geographically dispersed demanders (or suppliers). [...] if there are everywhere decreasing average costs of transmission whithin the network, such distribution systems are natural monopolies. Water supplies provides a simple illustration [...]" (Schmalensee, op. cit., p. 4). Daí as variadas técnicas de cobrança pelo uso da água e efluentes, como se infere de CARRERA-FERNANDEZ, José; GARRIDO, Raymundo-José. Economia dos recursos hídricos. Salvador: Edufba, 2002. p. 147-180. Ampliar em SERRA, Pedro. Águas e resíduos. In: VVAA. Conferências ERSE. Lisboa: Entidade Reguladora do Sector Eléctrico, 2000. p. 91-104.
} 
para fornecer outras prestações" ${ }^{11}$ A escolha do administrador público, portanto, será ótima quando recair sobre apenas uma empresa, pois a existência de outros prestadores do mesmo serviço conduzirá, inevitavelmente, ao aumento do custo unitário do serviço prestado (um mesmo produto ou serviço, muito mais oneroso ao usuário).

Mais ainda: seria inconcebível a construção de todo um sistema de tubulação e manilhas em paralelo ao já existente - isso sem se falar na estação de tratamento dos efluentes. Seria criado um custo público que geraria desperdício de verba - seja dos contribuintes, seja dos usuários. Significa dizer que um e somente um particular poderá prestar o serviço de saneamento na cidade de "B.": aquele que já dispõe da infraestrutura instalada.

\section{O escopo do processo licitatório e a inexigibilidade}

10. Fixada a premissa de que o serviço de saneamento básico, assim como o tratamento de resíduos, é monopólio natural, é indispensável que se faça o cotejo da situação concreta com a previsão legal de inexigibilidade de licitação. Com efeito, a Consulente não apenas possui a infraestrutura necessária à prestação do serviço que, frise-se, já vem sendo prestado em referência às indústrias da região, como também possui estação de tratamento de resíduos líquidos e sólidos com capacidade ociosa. Detém, portanto, a possibilidade concreta de atender a toda a demanda da população de "B.". A questão que se coloca, portanto, é justamente aquela referente ao quesito supraformulado: há necessidade e/ou possibilidade de licitação válida, no caso em comento?

Como todos os casos de inexigibilidade de licitação, aqui o mundo dos fatos impera. Basta investigar o escopo das licitações públicas e por que, em algumas situações fáticas, elas se tornam inexigíveis.

11. A licitação tem como objetivo a celebração do contrato mais vantajoso possível à administração, tendo em vista a necessidade pública previamente definida pela autoridade competente. A escolha pública dá-se quanto à alocação de verbas orçamentárias no tipo de obra e/ou serviço a ser executado - con-

\footnotetext{
${ }^{11}$ Justen Filho, op. cit.
} 
jugada com a definição objetiva dos característicos que, na visão técnica da administração, autorizam que uma pessoa privada execute tal contrato. Esta escolha, oriunda da capacidade de gestão de determinados órgãos públicos, definirá o objeto e o conteúdo do futuro contrato administrativo.

Ora, todos os contratos administrativos têm como pressuposto um juízo fundamentado quanto à sua necessidade, utilidade e moralidade. A instalação (ou não) do processo de licitação pressupõe essa definição prévia. Como consignou Sérvulo Correia:

O acto inicial - que denominamos decisão ou deliberação de contratar - envolve necessariamente a apreciação de um ou mais interesses públicos cuja prossecução represente atribuição do Estado e a identificação do contrato e, dentro deste amplo gênero, de um contrato com determinada causa-função, como meio mais idôneo para satisfazê-los. ${ }^{12}$

Esta deliberação de contratar define o objeto e o conteúdo do contrato, bem como a verba pública a ser nele despendida (e respectiva fonte de custeio). A finalidade da licitação, portanto, é realizar um processo eficiente que culmine na contratação mais vantajosa para a administração, tendo em vista o previamente estudado e definido.

O ato que fundamenta a conveniência da contratação reporta-se ao motivo - de fato e de direito - de uma decisão administrativa (salvo as exceções das contratações urgentes e emergenciais, as quais podem ser praticadas de imediato). $\mathrm{O}$ agente administrativo tem o dever de declinar previamente a motivação que justifique aquela específica contratação como útil, adequada e vantajosa, revelada como o meio mais idôneo para o atendimento do interesse público no caso concreto.

12. A questão principal, objeto de análise por este parecer, consiste na possibilidade de licitação, pela Prefeitura Municipal de "B.", para contratação de prestador de serviço público de saneamento básico. Para análise do questionamento, ao menos dois diplomas legais devem ser analisados, quais sejam, a Lei oํ 8.666/1993 (Lei de Licitações), assim como a Lei no 11.445/2007 (Lei de Diretrizes Nacionais para o Saneamento Básico).

${ }^{12}$ CORREIA, Sévulo. Legalidade e autonomia contratual nos contratos administrativos. 1. reimp. Coimbra: Almedina, 2003. p. 537-538. 
13. A primeira constatação, imprescindível para que se desenvolva a tese ora esboçada, é a de que é plenamente possível a prestação do serviço de saneamento básico por particulares. A política pública de saneamento é construída pelo ente público, porém sua execução pode ficar a cargo de empresa privada: esta é a racionalidade da Lei no $11.445 / 2007$. Basta que, como no caso em exame, à pessoa privada tenha sido legitimamente outorgada a execução do serviço público.

Não se discute, no âmbito deste parecer, qual a melhor forma de contratação do privado para execução dos serviços, partindo-se do pressuposto inafastável de que, independentemente de qual modalidade de contratação, deve-se analisar a viabilidade de licitação. Com efeito, é por meio de licitação que o poder público, no mais das vezes, contrata privados para a prestação de serviços públicos. A Lei no 8.666/1993 estabelece o regime jurídico aplicável às licitações e contratos administrativos, assim como os casos em que não será necessário, ou mesmo possível, a licitação do serviço público. Delimitando o exame ao objeto principal do parecer, trata-se aqui da chamada inexigibilidade de licitação.

13.1 É incontroverso - tanto na doutrina como na jurisprudência - que a possibilidade de contratação direta, isto é, sem licitação, é efetiva exceção à regra geral de necessidade de procedimento licitatório prévio (razão pela qual deve ser analisada com cautela). Como primeiro ponto necessário, deve-se fazer menção ao fato de que a licitação somente se justifica quando há possibilidade de competição entre particulares.

A justificativa é lógica: havendo apenas um particular em condições de prestar o serviço, ou seja, de ser contratado, seria absurdo sustentar a necessidade de licitação. O mesmo deve ser dito quanto a licitações cuja realização venha a gerar expressivos prejuízos ao erário e/ou aos usuários dos serviços públicos - aquelas despidas de qualquer racionalidade econômica, que apenas impliquem a multiplicação desnecessária de custos públicos. Realizar o processo licitatório em situações fáticas desarrazoadas e desproporcionais como as ora descritas implica séria violação à Constituição do Brasil e à Lei no 8.666/1993 (entre outros diplomas legais).

O dever de licitar, portanto, não é absoluto e sua inexigibilidade ou dispensa só pode ser analisada diante de um caso concreto. Não é possível, in abstrato, que se relacionem hipóteses taxativas de inexigibilidade de licitação, pois as vicissitudes de cada caso deverão indicar a conclusão a ser tomada. 
Partindo-se do pressuposto de que não é possível licitação quando não haja viabilidade de concorrência e fazendo o cotejo com a situação ora analisada, é de se analisar a possibilidade de prestação do serviço de saneamento básico por mais de uma empresa.

13.2 Conforme já afirmado, a inexigibilidade de licitação está intimamente ligada à impossibilidade fática de competição entre particulares. Se é certo que se está diante de um monopólio natural (como de fato o é), deve-se compreender que a competição é inviável, em especial pela existência de infraestrutura já construída, em pleno funcionamento e com capacidade ociosa, de titularidade da Consulente.

A situação excepcional, que justifica a impossibilidade de competição, está fundada no fato concreto de que a eventual escolha de outra empresa para a prestação dos serviços implicará a quebra do monopólio natural, com a duplicação de infraestrutura já existente (o que não é viável, econômica e logicamente). $\mathrm{O}$ mesmo se diga quanto ao fato de que os custos para contratação de outro particular serão excessivamente superiores, e, portanto, igualmente inviáveis em comparação aos custos estimados para utilização da rede de infraestrutura da Consulente.

Veja-se que a escolha colocada à administração pública não é, em verdade, uma alternativa possível no mundo dos fatos (e por isso não é válida perante o direito). A construção de nova rede de esgotos e novo terminal de tratamento é inviável - seja do ponto de vista do investimento necessário, seja do ponto de vista da manutenção econômico-financeira do empreendimento. Isso sem se falar na ausência de razoabilidade, proporcionalidade e economicidade em tal escolha: a rigor, instalar a licitação implicaria celebrar a hipótese menos vantajosa para a administração municipal.

14. Assim, dúvidas não podem existir quanto ao fato de ser inexigível a licitação para a prestação dos serviços de saneamento na cidade de "B.", visto que, na lição de Celso Antônio Bandeira de Mello, somente são licitáveis objetos que possam ser fornecidos por mais de uma pessoa, ${ }^{13}$ o que efetivamente não é o caso da situação fática em exame.

A conclusão embasa-se nas vicissitudes do caso concreto, que orientam a interpretação de que há uma e somente uma alternativa satisfatória para

\footnotetext{
${ }^{13}$ Mello, op. cit., p. 530.
} 
o excelente atendimento do interesse público, justificando a inexigibilidade do procedimento licitatório. Com efeito, e exatamente nos termos antes dispostos, não há alternativa viável ou justificável a ser adotada pela administração pública.

Muito embora seja possível que se pense na possibilidade de construção e/ou duplicação da infraestrutura já existente, tal opção não satisfaz, ainda que minimamente, o interesse público. A escolha do administrador público deve ser pautada pelas razões que justificam a escolha mais eficiente e vantajosa. Não há motivo lógico para concluir que haja alternativa mais vantajosa ao poder público e à sociedade do que a utilização da infraestrutura já existente e em pleno funcionamento.

15. Note-se que a inexigibilidade de licitação pode estar vinculada tanto a peculiaridades do sujeito a ser contrato, quanto ao objeto da contratação - sendo este último o tema ora analisado. Nesses casos, e conforme leciona Marçal Justen Filho, é possível que haja inviabilidade de competição fundada na natureza da atividade a ser desenvolvida. ${ }^{14}$ Afinal, o rol consignado no artigo 25 da Lei no 8.666/1993 é numerus apertus, meramente exemplificativo. Serão os fatos que determinarão, neste ou naquele caso, a inexigibilidade da contratação.

Definida a necessidade de contratação dos serviços, portanto, verifica-se que há apenas uma alternativa válida à administração pública: a de contratar o particular que possui a infraestrutura necessária para a prestação do serviço. No caso em tela, tal particular é a Consulente.

16. Ora, é plenamente válido que se firme a justificativa de inexigibilidade no caput do art. 25 da Lei nº 8.666/1993, para além das hipóteses exemplificativas que constam dos seus incisos. Mas, tal como leciona Marçal Justen Filho, a existência dos incisos no art. 25 não pode ser vista como destituída de sentido, visto que, além de exemplificar casos em que há inexigibilidade de licitação, também servem de parâmetros, requisitos e pressupostos para a contratação direta. ${ }^{15}$ Nesse sentido, a análise que deve preceder à

\footnotetext{
${ }^{14}$ JUSTEN FILHO, Marçal. Comentários à Lei de Licitações e Contratos Administrativos. 14. ed. São Paulo: Dialética, 2010. p. 358.

${ }^{15}$ Ibid., p. 360.
} 
conclusão pela invisibilidade de licitação deverá perpassar requisitos técnicos e econômicos em referência ao objeto da contratação.

Economicamente, o custo para a ligação da rede de esgoto doméstica com a rede coletora já existente na cidade de "B." é infinitamente menor do que o custo para a construção de nova rede (na eventualidade de se entender que a construção de infraestrutura paralela seja possível). Socialmente, as obras em menor proporção gerarão menores transtornos aos cidadãos do município. Tecnicamente, é viável a conexão mencionada, pela construção da rede e de estações elevatórias, conforme documentação apresentada pela Consulente.

Aliado ao binômio economia e possibilidade técnica, deve-se entender que a Lei $\mathrm{n}^{\mathrm{o}}$ 8.666/1993 tem como um de seus pilares a preocupação com o menor custo possível. É evidente que a busca pelo menor preço não é absoluta, devendo ser sopesada com a necessária análise da viabilidade técnica e qualitativa do serviço prestado. Com efeito, a situação fática analisada leva à compreensão de que a melhor, senão única alternativa, seja do ponto de vista técnico, seja do ponto de vista econômico ou social, é a contratação direta da Consulente para a prestação do serviço de saneamento.

A questão é igualmente tratada por Marçal Justen Filho, ao analisar a inviabilidade de competição pela existência de monopólio (legal ou natural). ${ }^{16}$ O exemplo lá consignado é de grande valia para a compreensão do que se está aqui a tratar: é inviável a competição quando houver necessidade de transporte de mercadorias por linha férrea, visto que apenas o detentor da linha poderá efetuar o transporte. É, com efeito, insustentável pensar na existência de duas linhas férreas em paralelo, ligando as mesmas localidades. $\mathrm{O}$ mesmo raciocínio vale para a questão de tubulação de esgoto e sistema de tratamento dos efluentes.

No caso em exame, a escolha de outro particular para a prestação dos serviços, além de não ser tecnicamente possível, é economicamente inviável e inconveniente diante dos interesses públicos. Aliás, e como aponta Antonio Carlos Cintra do Amaral, nada de mais há quanto a casos excepcionais de dispensa e de inexigibilidade de licitação para concessões, permissões e autorizações de serviço público. ${ }^{17}$ Trata-se de dado usual do

\footnotetext{
${ }^{16}$ Ibid., p. 363.

${ }^{17}$ AMARAL, Antonio Carlos Cintra do. Concessão de serviço público. 2. ed. São Paulo: Malheiros, 2002. p. 27-29. No mesmo sentido: JUSTEN FILHO, Marçal. Teoria geral das concessões de servi-
} 
cotidiano, a impor a escolha pública que celebre a alternativa mais vantajosa para o caso concreto.

17. Desta forma, pode-se afirmar que a celebração da contratação direta nos casos em que estão satisfeitos os requisitos legais é dever do administrador público (tanto para a dispensa como para a inexigibilidade). Neste sentido já decidiu o TCU, em caso analógico e de plena aplicação ao presente:

[...] a dispensa de licitação, com fundamento no art. 24, inciso IV, da Lei no 8.666/93, se caracteriza como uma inadequação aos procedimentos normais de licitação, constituindo-se, sob esse prisma, num poderdever e não numa faculdade para o administrador, sob pena de ser responsabilizado pelos prejuízos que a sua inércia venha a causar, independentemente de qualquer planejamento. ${ }^{18}$

Quer-se com isso sublinhar que, havendo impossibilidade de competição conjugada com a necessidade de celebrar o contrato administrativo, a inexigibilidade da licitação é a consequência natural. Da mesma forma que a escolha indevida pela contratação direta pode vir a ser abusiva, a sua não doção pode caracterizar-se em violação aos deveres do administrador na busca da solução excelente ao interesse público.

Na situação em comento, não há margem de escolha, sob pena de responsabilização do agente público. Com efeito, a indevida realização da licitação inexigível sujeita os agentes por ela responsáveis a ressarcir integralmente os cofres públicos pelo montante gasto sem necessidade concreta. $\mathrm{O}$ simples fato de se lesar o patrimônio público já é causa bastante para que surja a obrigação de ressarcimento do erário (Lei no 8.429/1992, art. 5o). Mais ainda: no caso de haver a licitação inexigível, os responsáveis terão, em tese, praticado ato capitulado como improbidade. Afinal, a simples prática de atos que tragam prejuízo ao erário já bastaria para dar azo à incidência da

ço público. São Paulo: Dialética, 2003. p. 284-287; ROCHA, Cármen Lúcia Antunes. Estudo sobre concessão e permissão de serviço público no direito brasileiro. São Paulo: Saraiva, 1996. p. 115-116; DI PIETRO, Maria Sylvia Zanella. Parcerias na administração pública. 5. ed. São Paulo: Atlas, 2006. p. 137-138; SOUTO, Marcos Juruena Villela. Direito administrativo das concessões. 5. ed. Rio de Janeiro: Lumen Juris, 2004. p. 46-47; MOREIRA, Egon Bockmann. Direito das concessões de serviços públicos, op. cit., p. 103-104.

${ }^{18}$ AC no 1876-38/2007, Plenário, min. Aroldo Cedraz, j. 12/9/2007. 
Lei de Improbidade (art. 10o). ${ }^{19}$ Por outro lado, incidem as prescrições no art. 11 da Lei de Improbidade, relativas aos atos "que atentam contra os princípios da Administração Pública", conforme decidiu o STJ: "[...] a lesão a princípios administrativos contida no art. 11 da Lei no 8.429/92 não exige dolo ou culpa na conduta do agente, nem prova da lesão ao erário público. Basta a simples ilicitude ou imoralidade administrativa para restar configurado o ato de improbidade". ${ }^{20}$

Com efeito, os valores lesados são perfeitamente contemplados nos núcleos de "legalidade", "imparcialidade" e "eficiência" previstos no caput do art. 11 da Lei no 8.429/1992.

\section{Conclusão}

18. A análise da situação descrita antes conduz, portanto, a duas conclusões inafastáveis: a primeira, de que estão configurados todos os elementos necessários à contratação direta para prestação dos serviços de saneamento e tratamento de água e esgoto, por se tratar de monopólio natural; a segunda, de que esta contratação deve ser feita com a Consulente, que já possui a infraestrutura necessária à prestação do serviço, bem como a respectiva capacidade técnico-operacional. Trata-se da hipótese fática de contratação mais vantajosa para a administração pública.

Em conclusão, forneço as seguintes respostas aos quesitos formulados:

a. A prestação de serviços de saneamento, em específico a coleta de esgoto para posterior tratamento, constitui um monopólio natural?

Sim, a prestação de serviços de saneamento, assim como de tratamento de resíduos sólidos e líquidos é típico exemplo de monopólio natural.

b. É juridicamente válida a instauração de licitação para a construção duplicada de rede de esgotos e tratamento à semelhança daquela já existente? Não é juridicamente válida a instauração de licitação para a construção da rede de esgotos e tratamento, por tratar-se de serviço que só pode ser prestado de forma eficiente por uma empresa, sob pena de inviabilidade

\footnotetext{
${ }^{19}$ A aplicação das sanções da Lei no 8.429/1992 no caso de prejuízo ao erário pode se dar de modo objetivo. Neste sentido o REsp 940.629/DF, min. Teori Albino Zavascki, DJe 4/9/2008.

${ }^{20}$ REsp 988.374/MG, min. Castro Meira, DJe 16/5/2008.
} 
econômica do empreendimento e desperdício de recursos públicos. Configura-se nítido caso de inexigibilidade de licitação.

c. Pode a administração pública fazer escolhas discricionárias no caso em concreto, para a implantação de nova rede paralela à já existente?

Havendo inexigibilidade fática de licitação, a discricionariedade só pode ser bem compreendida a partir do reconhecimento de que a melhor solução possível é, também, a única válida. No caso concreto, a conjugação do interesse público em fornecer serviços de coleta, esgotamento e tratamento de efluentes (já definido em Lei e em atos administrativos) com a infraestrutura de monopólio natural preexistente exige a contratação direta como dever da administração.

É o parecer.

Curitiba, agosto de 2010.

Egon Bockmann Moreira

\section{Referências}

AMARAL, Antonio Carlos Cintra do. Concessão de serviço público. 2. ed. São Paulo: Malheiros, 2002.

ARAÚJO, Fernando. Introdução à economia. Coimbra: Almedina, 2002.

CARRERA-FERNANDEZ, José; GARRIDO, Raymundo-José. Economia dos recursos hídricos. Salvador: Edufba, 2002.

CORREIA, Sévulo. Legalidade e autonomia contratual nos contratos administrativos. 1. reimp. Coimbra: Almedina, 2003.

DI PIETRO, Maria Sylvia Zanella. Parcerias na administração pública. 5. ed. São Paulo: Atlas, 2006.

GONÇALVES, Pedro. A concessão de serviços públicos. Coimbra: Almedina, 1999.

GRAU, Eros. Ensaio e discurso sobre a interpretação/aplicação do direito. 3. ed. São Paulo: Malheiros, 2005.

HESSE, Konrad. Elementos de direito constitucional da República Federal da Alemanha. Tradução de L. A. Heck. Porto Alegre: S.A. Fabris, 1998. 
JUSTEN FILHO, Marçal. Comentários à Lei de Licitações e Contratos Administrativos. 14. ed. São Paulo: Dialética, 2010. . Serviço público no direito brasileiro. RDPE, v. 7, n. 161, 2004. . Teoria geral das concessões de serviço público. São Paulo: Dialética, 2003.

MELLO, Celso Antônio Bandeira de. Curso de direito administrativo. 25. ed. São Paulo: Malheiros, 2008.

MOREIRA, Egon Bockmann. Direito das concessões de serviços públicos. São Paulo: Malheiros, 2010.

. Processo administrativo. 4. ed. São Paulo: Malheiros, 2010.

NEVES, Castanheira. Metodologia jurídica. Coimbra: Coimbra Ed., 1993.

NUSDEO, Fábio. Curso de economia: introdução ao direito econômico. 5. ed. São Paulo: Revista dos Tribunais, 2008.

ROCHA, Cármen Lúcia Antunes. Estudo sobre concessão e permissão de serviço público no direito brasileiro. São Paulo: Saraiva, 1996.

SCHMALENSEE, Richard. The control of natural monopolies. Lexington: Lexington Books, 1979.

SERRA, Pedro. Águas e resíduos. In: VVAA. Conferências ERSE. Lisboa: Entidade Reguladora do Sector Eléctrico, 2000. p. 91-104.

SOUTO, Marcos Juruena Villela. Direito administrativo das concessões. 5. ed. Rio de Janeiro: Lumen Juris, 2004.

VARIAN, Hal R. Intermediate microeconomics. $5^{\text {th }}$. ed. New York: W.W. Norton, 1999.

VISCUSI, W.K.; VERNON, J.M.; HARRINGTON JR., J.E. Economics of regulation and antitrust. $3^{\text {rd }}$. ed. Cambridge: MIT Press, 2001.

WATERSON, Michael. Regulation of the firm and natural monopoly. Oxford: Basil Blackwell, 1988. 